\title{
GEER, the Multidisciplinary Spanish Society for Spine Specialists
}

\author{
F. Pellisé • I. González-Barrios • M. Aebi
}

Received: 13 July 2011/Published online: 18 August 2011

(C) Springer-Verlag 2011

In 1981, a group of orthopedic surgeons and physical medicine and rehabilitation specialists founded the first multidisciplinary spine society in Spain, under the name of GIEDER (Grupo Ibérico de Estudio de las Deformidades del Raquis or Iberian Group for the Study of Spinal Deformities). Eleven years later, this multidisciplinary group of physicians dedicated entirely to the assessment and care of patients with spinal disorders adopted a new name: GEER (Grupo de Estudio de Enfermedades del Raquis or Spinal Disorders Study Group). Since then, GEER has grown exponentially, during a time when health care delivery has changed rapidly and unpredictably, and spine care has been under the microscope [1]. Besides Europe, GEER has established close links with Latin America, and in the early 1990s founded with several South American Spine Societies SILACo (Sociedad Ibero Latino Americana de Columna or Iberian and Latin American Spine Society), the largest worldwide Spanishspeaking Spine Society.

Nurtured by many outstanding leaders, GEER adopted very rapidly a proactive attitude that enabled it to enter adulthood as a highly respected professional society. Based on its awareness of the relevance of outcomes research in the new millennium, GEER sponsored several task forces

F. Pellisé $(\bowtie)$

Spine Unit, Hospital Vall d'Hebron, Pg Vall d'Hebron 119-129, 08034 Barcelona, Spain

e-mail: 24361fpu@comb.cat

I. González-Barrios

Spine Unit, Anatomy Department, University Hospital Reina

Sofia, Córdoba University, Córdoba, Spain

M. Aebi

MEM Research Center for Orthopaedic Surgery,

University of Bern, Bern, Switzerland in 2000 to standardize patient outcome assessment by developing validated Spanish outcome measures. As a result of this effort, the GEER Deformity Task Force published one of the first transcultural adaptations of the SRS-22 outcome measure [2] and participated actively in refining the final version $[3,4]$ before it became the global scoliosis outcome measure. Simultaneously, the GEER Back Pain Task Force provided the first available data [5, 6] on the psychometric characteristics of the Deyo Core Set Outcome Measure, further modified to become the COMI [7], the main outcome measure of the International EuroSpine Tango Registry. In addition, GEER has continuously improved its research and educational offer (http://www.geeraquis.org) and linked its website patient area to the Spanish version of the EuroSpine Patient Line. In May 2010, Patient Line was the most frequently visited area of the EuroSpine website, and Spanish documents were the ones most often accessed [8]. Since 2009, GEER has awarded grants to young trainees to complete the EuroSpine Education Program [9]. A few months ago the first graduates of these modular courses received their certificate, establishing a landmark in the effort to offer independent educational programs on the way to a Spine Specialist recognition in Europe. It is expected that the first module of the EuroSpine Diploma courses in Spanish will be delivered by GEER during 2011.

In 2005, GEER became an affiliated society of the European Spine Journal, and since then, the abstracts of its annual meeting have been regularly published. This special GEER supplement of the European Spine Journal follows other National European supplements [10], in keeping with the trend initiated by the Journal, the EuroSpine Foundation, and EuroSpine to increase mutual collaboration among the various European National Spine Societies. The papers included in this supplement are blindly 
peer-reviewed and selected by the GEER Scientific Committee from the abstracts submitted to the 2010 GEER Annual Meeting. We wish you fruitful reading.

\section{Conflict of interest None.}

\section{References}

1. Lee C (1995) Challenges of the spine specialists. North American Spine Society Presidential Address. Spine 20:1749-1752

2. Bago J, Climent JM, Ey A, Perez-Grueso FJ, Izquierdo E (2004) The Spanish version of the SRS-22 patient questionnaire for idiopathic scoliosis: transcultural adaptation and reliability analysis. Spine 29:1676-1680

3. Asher MA, Lai SM, Glattes RC, Burton DC, Alanay A, Bago J (2006) Refinement of the SRS-22 Health-Related Quality of Life questionnaire Function domain. Spine 31:593-597
4. Bago J, Climent JM, Ey A, Perez-Grueso FJ, Izquierdo E (2006) Re: Asher MA, Lai SM, Glattes RC et al. Refinement of the SRS-22 questionnaire Function domain. Spine 2006;31:593-597. Spine 31(15): 1758

5. Pellisé F, Alvarez L, Escudero O, Pont A, Ferrer M (2003) Metric characteristics of the six-question "core set" in the evaluation of back pain. Eur Spine J 12(Suppl 1):S12-S13

6. Ferrer M, Pellisé F, Escudero O, Alvarez L, Pont A, Alonso J, Deyo R (2006) Validation of a minimum outcome core set in the evaluation of patients with back pain. Spine 31(12):1372-1379

7. Mannion AF, Elfering A, Staerkle R, Junge A, Grob D, Semmer NK, Jacobshagen N, Dvorak J, Boos N (2005) Outcome assessment in low back pain: how low can you go? Eur Spine $\mathbf{J}$ 14:1014-1026

8. Pellisé F, Sell P, EuroSpine Patient Line Task Force (2009) Patient information and education with modern media: the Spine Society of Europe Patient Line. Eur Spine J Suppl 3:395-401

9. Aebi M (2010) Education program of EuroSpine/The Spine Society of Europe. Eur Spine J 19:1-2

10. Lamartina C (2009) Introduction for GIS-supplement. Eur Spine J 18(Suppl 1):S1 